\title{
LEITOR, IMAGEM, FRAGMENTO: O PENSAMENTO DE ROLAND BARTHES NA RELAÇÃO LEITOR-TEXTO-AUTOR
}

Márcio Venício Barbosa*

RESUMO:

Propõe-se aqui uma leitura de Barthes pela simpatia, pela partilha do mesmo páthos, que, no caso barthesiano, é o questionamento da linguagem - a do autor ou a do objeto de seu texto -, que o faz sempre modificar seu percurso, buscando, mesmo momentaneamente, expressar-se fora das imposições da Doxa.

PALAVRAS-CHAVE: Roland Barthes, leitor, texto, autor.

Sempre me impressionou, nas leituras de Barthes - tanto as que ele fez, quanto as que dele fizeram - algo que, de certa forma, está além do próprio discurso, uma espécie de pathos comum a toda um grupo de autores, ocupados, sim, com a literatura, mas também com toda sorte de linguagem. Cientificidade, adesão a um campo específico do saber não foram, nos estudos barthesianos, uma razão em si para a configuração de um discurso inclassificável, mas o que parece dar coesão e sustentação a esses estudos é a afinidade, uma afeição por uma voz e o que ela propõe, não como "objetos", mas como elementos a serem atacados, no sentido bélico, para que o sentido permanecesse à deriva.

A maioria dos autores-amigos de Barthes - Todorov, Kristeva, Derrida, Genette, Baudrillard - freqüentou seus seminários, seja expondo aos participantes seu campo de saber, como convidados, seja como assistentes ou aspirantes a um doutorado. Foi nos seminários de Barthes que Kristeva introduziu, na França, a leitura de Bakthin e o conceito de plurilingüismo no romance; e foi também nesse espaço que Baudrillard começou a desenvolver seu "sistema dos objetos".

* Doutor em Letras: Literatura e outros Sistemas Semióticos (Área de concentração: Literatura Comparada), 2004. 


\section{EMTESE}

Belo Horizonte, v. 9, p. I-28I, dez. 2005

Essa afinidade, ou, antes, essa amizade que se verifica entre os interlocutores de Barthes, leva-me, portanto, a falar do lugar da amizade. Não uma amizade no sentido cotidiano do termo, ou não apenas essa amizade. "Il faut s'efforcer de parler de l'amitié comme d'une pure topique..." (Barthes, 1995: 67. Grifo do autor). Sinto-me também atingido por esse pathos e, longe de querer assumir o "Roland-Barthes" como linguagem, pretendo apenas falar dos aspectos escolhidos para este trabalho com simpatia, no sentido grego do termo: acometido do mesmo

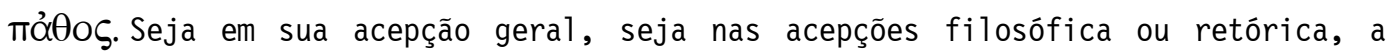
palavra grega reúne aspectos que convêm ao que proponho como uma leitura pela simpatia, que não tem paralelo no gosto, uma vez que pressupõe também o des-gosto: pode-se amar o tempo todo?

Tendo a chamar a quase totalidade dos textos de comentaristas de Roland Barthes de leituras da simpatia, pois não escondem sua afeição, sua amizade pelo tema sobre o qual discorrem e, por isso mesmo, são lidos também com simpatia. E esse tipo de leitura não exclui, por fim, uma possível oposição, um embate, no centro de uma "comunidade discursiva", como essa que se foi formando em torno de Barthes e de seus textos. A proposta de Bernard Comment (2002), em Roland Barthes, vers le neutre, que é a de que o neutro seria o "projeto" da obra de Barthes pode ser vista como contrária a essa mesma obra, marcada pelo movimento, mas não deixa de ser uma abordagem possível, uma vez que identifica, no percurso do autor, essa obsessão pelo neutro. Igualmente limítrofe é a proposta de Carpentiers (1998), que busca na análise dos escritos de Barthes, senão a possibilidade de se constituir uma "teoria da leitura", pelo menos a constatação de que ali se encontram os primeiros esboços, as primeiras visadas de uma abertura para o leitor que teorias subseqüentes viriam a explorar. Não foi por incapacidade que Barthes não propôs teoria alguma, o que colaborou para que não ganhasse a simpatia dos franceses, em geral, mas por estar convicto do caráter provisório do discurso e das impossibilidades de uma teoria nesse campo:

Je crois en effet qu'il ne faut pas céder trop vite au mythe selon lequel la théorie vient renflouer la pratique, qui, à son tour, redresse la théorie. Cette dialectique, vraie dans le politique, ne saurait être aussi simple dans l'espace du langage (Barthes, 1994: 338). 
Assim como Bernard Comment, que propõe uma abordagem ampla da obra barthesiana, a proposta de Carpentiers evidencia uma quase necessidade, que poderia ser chamada de "natural", no sentido barthesiano do termo: a busca de um sentido, um construto, um fio de Ariadne que explique uma obra tão diversa ou, em outras palavras, uma obra em movimento. Daí a tentativa de explicar a ausência de uma teoria da leitura em Barthes, embora todos os elementos para isso já estivessem indicados em um ou outro ponto de sua obra, que Carpentiers levanta minuciosamente.

Ora, mais que o texto em si ou que seu autor, os dois outros termos da relação que pretendo abordar aqui, o leitor é aquele que faz circular o sentido, que pode observar o plural de que o texto é feito, mas pode, também, trazer ao texto seu próprio plural. E é esse aspecto de Barthes que nos interessa: um leitor, visto através de suas imagens e de alguns fragmentos, feitos, evidentemente, de escolhas e simpatias.

Ao final de "La mort de l'auteur", Barthes afirma que, para que a escritura tivesse um futuro, seria necessário inverter um mito, ou seja, tornar possível, com a morte do autor, o nascimento do leitor. E sobre o leitor, a leitura, seus trabalhos seguintes apresentarão considerações de grande interesse, que dão sustentação à tese de Carpentier. Essas considerações são marcadas por uma figura recorrente em seu discurso: o plural. Uma leitura plural, de acordo com a proposta que abre S/Z (Barthes, 1994: 555-742), rompe com a noção de leitura cristalizada no senso comum. $S / Z$ é o próprio teatro dessa nova leitura, trazida à cena com todos os personagens, numa produção que não é mais pronta, acabada pela encadernação de um livro e pelas "explicações" de um grande mestre. Esses personagens: autor-textoleitor, sendo que o primeiro perde, devidamente, seu espaço tradicional, não são mais vistos como unidades. 0 Eu e o texto da frase que Barthes analisa ("Je lis le texte.") são instâncias plurais: "Plus le texte est pluriel et moins il est écrit avant que je le lise" (Barthes, 1994: 561).

Todo o universo da leitura se modifica com essa frase, que marca a abertura para uma nova percepção da literatura, atacando, a um só tempo, as três instâncias que 1he dão sustentação e permitem sua circulação na sociedade: autor, texto e leitor. 


\section{EMTESE}

Belo Horizonte, v. 9, p. I-28I, dez. 2005

A primeira dessas instâncias, que recebe, então, um golpe mortal, é o autor. Por que escolher, para esse exercício de leitura, um autor clássico? Um autor contemporâneo, que se pudesse facilmente inscrever na linhagem de Mallarmé (o verdadeiro "autor" da morte do autor, tanto na visão de Barthes como na de Blanchot ou Foucault), que estivesse ocupado com o acontecimento da linguagem no texto, poderia, talvez, fazer com que as idéias ali apresentadas parecessem limitadas a uma narrativa contemporânea, o que criaria um novo leitor, sim, mas não abriria de imediato uma nova vertente para a leitura. A imagem do autor, presente no texto agora apenas pelo traço de sua escritura, um corpo sem exterioridade para além do texto, se confirma no Balzac que se encontra nessa leitura de Sarrazine.

Entretanto, ainda que sofrendo essa morte conceitual, no sentido de uma tradição que o colocava acima do comum dos mortais, vendo na sua produção não o texto, destinado à fruição, mas a expressão do engenho e da arte, ou do Gênio, como ainda quer Bloom (2003), resta ao autor uma saída nesse embate. Uma saída desprovida de glória, mas aberta a uma maior produtividade:

L'Auteur lui-même - déité quelque peu vétuste de l'ancienne critique - peut, ou pourra un jour constituer un texte comme les autres: il suffira de renoncer à faire de sa personne le sujet, la butée, l'origine, l'autorité, le Père, d'où dériverait son œuvre, par une voie d'expression; il suffira de le considérer lui-même comme un être de papier et sa vie comme une biographie (au sens étymologique du terme), une écriture sans référent, matière d'une connexion, et non d'une filiation: l'entreprise critique (si l'on peut encore parler de critique) consistera alors à retourner la figure documentaire de 1'auteur en figure romanesque, irrepérable, irresponsable, prise dans le pluriel de son propre texte: travail dont l'aventure a déjà été racontée, non par des critiques, mais par des auteurs eux-mêmes, tels Proust et Jean Genet (BARTHES, 1994, 697).

Esse autor, ser de papel, retomando outra categoria barthesiana, se distanciaria do escrevente, e se afirmaria como escritor, por esse trabalho marcado pela preocupação com a linguagem e, em última instância, pelo plural, pelo dialogismo, pelo carnavalesco e pela polifonia de Bakthin (1978). 0 Barthes de papel só se apreende na multiplicidade, na pluralidade. A ele se aplica o que diz de Proust e Genet: ele é um autor que retorna amigavelmente. Um retorno que não é ressurreição, uma vez que a escrita, mesmo com sua vocação para o eterno, se instaura no campo do silêncio, da morte. 
Le plaisir du Texte comporte aussi un retour amical de 1'auteur. L'auteur qui revient n'est certes pas celui qui a été identifié par nos institutions (hoistoire et enseignement de la littérature, de la philosophie, discours de l'Église); ce n'est même pas le héros d'une biographie. L'auteur qui vient de son texte et va dans notre vie n'a pas d'unité; $i l$ est un simple pluriel de "charmes", le lieu de quelques détails ténus, source cependant de vives lueurs romanesques, un chant discontinu d'amabilités, en quoi néanmoins nous lisons la mort plus sûrement que dans l'épopée d'un destin; ce n'est pas une personne (civile, morale), c'est un corps (Barthes, 1994: 1044).

No início de seu curso sobre o Neutro, agora livro, Barthes apresenta a "biblioteca de autores mortos" da qual seriam extraídas as trinta figuras escolhidas para apresentar o tema, e faz uma declaração que reflete a amizade, a simpatia com que se aproxima dos autores escolhidos:

Lire 1'auteur mort est, pour moi, vivant, car je suis troublé, déchiré par la conscience de la contradiction entre la vie intense de son texte et la tristesse de savoir qu'il est mort: je suis tourjours triste de la mort d'un auteur, ému par le récit des morts d'auteur (Tolstoï, Gide). $\rightarrow$ Le deuil est vivant. (Barthes, 2002: 35).

É como se o autor, agora instância de papel, retornasse, também ele, como um texto: "L'interlocuteur étant un texte, le sujet est aussi un texte" (Kristeva, 1969: 121). Conclusões como essa de Kristeva colaboraram para que uma noção de texto bastante ampliada se impusesse: tudo é texto!, foi o que se passou a ouvir em determinado momento dos estudos literários. De fato, o aprofundamento da semiologia estruturalista e a construção de discursos sobre os vários sistemas semióticos expunham, nos produtos desses sistemas, um funcionamento semelhante a esse produto do sistema lingüístico, o texto. A possibilidade de se construir no senso comum um enunciado como "tudo é texto" vem da preponderância dada ao sistema lingüístico pela semiologia.

Nesse espaço crítico, as figuras barthesianas se sobrepõem. Texto, prazer, escritura tornam-se termos correntes e, pelo menos os dois últimos, que escapam do uso comum que têm fora dos estudos literários, são logo identificados com Barthes. Entre seus escritos, vários tratam desses temas, mas destacam-se $S / Z$, Le Plaisir du texte e o artigo "Texte (théorie du)", escrito para a Encyclopaedia Universalis. Neste último, após um relato do percurso da noção de texto que chega até sua adoção pela semiótica literária, Barthes mostra a importância dos estudos lingüísticos, com a poética de Jakobson, para uma abordagem da literatura que a 


\section{EMTESE}

Belo Horizonte, v. 9, p. I-28I, dez. 2005

liberava de um historicismo estéril e aponta também seu limite: a frase. Surge daí, a necessidade da noção de texto:

... mais au-delà de la phrase? Quelles sont les unités structurales du discours (si l'on renonce aux divisions normatives de la rhétorique classique)? La sémiotique littéraire a eu besoin ici de la notion de texte, unité discursive supérieure ou intérieure à la phrase, toujours structuralement différente d'elle (Barthes, 1994: 1679).

Em seguida, o autor apresenta uma teoria do texto, atribuindo a Kristeva os conceitos teóricos que apresenta: práticas significantes, produtividade, significância, feno-texto e geno-texto, inter-textualidade. Destaca-se, nesses conceitos, a significância, "lueur, fulguration imprévisible des infinis de langage" (Barthes, 1994: 1685), trabalho infinito do significante que separa de vez os conceitos de texto e obra: esta se segura na mão, aquele se mantém na linguagem.

Outro aspecto que se destaca a partir da teoria do texto é o advento do leitor sobre a cena teórica. Nasce da entrada definitiva do leitor nesse domínio a noção de escrever a leitura e, daí, a noção de escritura tal qual Barthes a apresenta:

La pratique d'une écriture textuelle est la véritable assomption de la théorie du texte: elle est donc destinée plus aux sujets-producteurs d'écriture qu'aux critiques, aux chercheurs, aux étudiants. Cette pratique (si l'on veut la différencier du simples travail du style) suppose qu'on a dépassé le niveau descriptif ou communicatif du langage, et qu'on est prêt à mettre en scène son énergie génératrice; elle implique donc qu'on accepte un certain nombre de procédures: le recours généralisé aux distorsions anagrammatiques de l'énonciation (aux "jeux de mots"), à la polysémie, au dialogisme ou inversement à l'écriture blanche, qui déjoue, déçoit les connotations, aux variations "irrationnelles" (invraisemblables) de la personne et du temps, à la subversion continue de la relation entre l'écriture et la lecture, entre le destinateur et le destinataire du texte. Il s'agit donc d'une pratique qui est fortement transgressive par rapport aux principales catégories qui fondent notre socialité courante: la perception, l'intellection, le signe, la grammaire et même la science (Barthes, 1994: 1689).

Porém, ainda somos leitores que se assemelham ao "olhador" de quadros:

preferimos a ilusão de real que se estabeleceu no figurativismo desde a Renascença, assim como preferimos uma literatura conforme a uma organização "natural" da linguagem literária e, por conseguinte, uma crítica igualmente "natural". Há toda uma problemática em torno do prazer do texto. 0 próprio conceito de prazer já é uma verdadeira encruzilhada epistemológica, que não pode ser dissociado de a) 
"princípio de prazer"/"princípio de realidade", em Freud; b) ainda em Freud, "desejo inconsciente" - que se manifesta no sonho, no recalque, no chiste...; c) o "desejo do desejo do outro", em Lacan; d) "agenciamento de desejo", em Deleuze e Guattari; e) "uso dos prazeres", em Foucault1. Não se trata, aqui, de uma simples escolha conceitual. A exposição que Barthes faz da noção de prazer associada ao texto, que não exclui, evidentemente, as noções de desejo e de gozo, pode muito bem ser reivindicada ou contestada por cada um dos construtos teóricos que enumeramos, apesar de comumente seus escritos serem associados à Psicanálise lacaniana, devido à relação de Lacan com o estruturalismo. Porém as leituras de Barthes, atestadas pela dinâmica de seus cursos, não limitam esses conceitos apenas à leitura de Lacan.

Roland Barthes expõe, em sua crítica escritural, o prazer de um sujeito, que, como vimos, de acordo com a noção de "morte do autor", não precisa ser identificado com ele. Há ali um sujeito de papel, que fala, por fragmentos, de sua relação de gozo ou prazer com o texto. Esse sujeito nada mais é que um leitor que reflete sobre suas práticas de leitura. Ainda que pese o nome que assina o livro, nada nele autoriza que se o tome por um manual, mesmo que um fragmento ou outro conceitue essa relação do leitor com o texto de forma esclarecedora. Le Plaisir du texte diferencia, claro um "texto de prazer" de um "texto de gozo", sendo este último aquele que, por uma série de características que normalmente se encontram no texto moderno e que a teoria do texto, tal qual proposta por Kristeva, explicita, leva o leitor a querer falar dele, ou seja, leva o leitor à "leitura-escrita" ou à escritura, enquanto o outro pode proporcionar algum deleite, mas pode não provocar no leitor nenhuma reação. Após a leitura desse livro, o que se pode fazer é, simplesmente, perguntar: que textos me dão prazer? que textos exigem que eu fale deles? E ponto. Acaba aqui a contribuição do leitor-Barthes cujas marcas de autor se mostram nesse texto. Impossível transformar em "teoria" uma leitura ancorada no prazer. Aparece aqui o problema do "lastro cultural" que implica a noção de escritura. A história de leitor do sujeito que se manifesta de maneira fragmentada naquele livro permitiu-1he a enunciação de determinadas idéias que nada indica serem aplicáveis de imediato, caso contrário teríamos em Le Plaisir du texte um manual. 


\section{EM TESE}

Belo Horizonte, v. 9, p. I-28I, dez. 2005

Diante das novas possibilidades para ele abertas, o leitor que o texto solicita também é um novo leitor:

Un texte désire un lecteur simplement parce qu'il est écrit par un auteur. Le "je"qui parle demande en effet une voix qui lui réponde; c'est le modèle de tout échange, tel qu'on peut le saisir au niveau linguistique (Carpentiers, 1998: 149).

As exigências que se apresentam ao leitor são equivalentes àquelas que se fazem também ao autor e ao texto e é isto o que diferencia e encanta nessa proposta: autor, texto e leitor não têm nenhum tipo de preponderância um sobre o outro.

Fora quebrada a supremacia do "Autor" com a circulação de um rude enunciado, "a morte do autor", que teve a importante função prática de trazer à cena uma reflexão fundamental, com a atenção que ela merecia. Fora dessacralizada a "Obra", agora reduzida à sua materialidade prosaica, em proveito da instância discursiva do Texto. Com o fim dessas "entidades", o que se eclipsava eram as correntes críticas baseadas tanto na supremacia do Autor, como princípio e fim de toda leitura literária, quanto na pura imanência do texto. Nenhuma dessas correntes anteriores à proposta da crítica-escritura consideravam, a não ser como "consumidor", a instância do leitor.

Barthes abraça a teoria do texto, formulada por Kristeva, pois ali se encontram os elementos teóricos necessários para esse novo estado de coisas, entretanto, não propõe nenhuma teoria. Como vimos nas páginas anteriores, essa era uma possibilidade que o autor não chegava a cogitar. No entanto, sua posição de leitor dessas novas contribuições o colocaram em destaque como difusor de novas idéias e, nessa posição, cria-se a imagem do Barthes inovador, iconoclasta...

Se, por um 1ado, Barthes parece receber "indevidamente" os louros por idéias que ele teria apenas ajudado a difundir, por outro lado, seus escritos são, não o modelo de aplicação, mas uma demonstração da possibilidade de se acolher, na crítica, um sujeito tal e qual propunha a teoria do texto. Esse sujeito, pela repercussão de seu texto, pela circulação que eles tiveram, não só entre os intelectuais, mas também junto ao grande público, servia como 
uma passagem para as novas idéias críticas, pondo-as definitivamente em confronto com as idéias pré-concebidas.

Barthes assume, com relação à crítica e à literatura, a mesma posição que já lhe era cara com relação à pintura, à música, ao teatro, ao cinema... a de amador. 0 amador, segundo ele, diferencia-se do consumidor, pois seu corpo está em contato com a arte. Assim é o Barthes-pianista amador, amante de Schumann (aquele que sacrificou o próprio corpo à música); o Barthes-pintor amador, criador "irresponsável" de aquarelas cuja prazer estético chega a pôr em dúvida a atividade amadora; o Barthes-ator amador, no grupo de teatro antigo da Sorbonne e no papel de Thackeray, em Les Sœurs Brontë, filme de André Téchiné.

É esse mesmo amador que é preciso ver em seus textos, um sujeito "irresponsável", no sentido de não ter de prestar contas à Ciência, de não propor teorias, mas apenas apontar sua necessidade; um sujeito cujo corpo ainda chama por novas leituras, pois ainda há o que modificar no uso institucionalizante que se tem feito desses escritos.

NOTA:

1. Para a abordagem das noções de desejo e de gozo em Psicanálise, cf. Roudinesco (1998), que traz indicações bilbiográficas precisas nos verbetes correspondentes. Para a discussão das noções de desejo e prazer em Foucault e Deleuze, cf. Deleuze (1994), em um texto que analise vários livros de Foucault, procurando rastrear esses conceitos e explicitar suas diferenças, sobretudo na relação do prazer com o poder, desenvolvida por Foucault, à qual Deleuze contrapõe sua noção de agenciamento de desejo.

ABSTRACT :

This paper aims at reading Barthes through sympathy, through sharing the same páthos, whitch, as for Barthes, refers to the questioning of language - the language of the author, or of the object of his text, which makes him modify his path, while searching, even momentarily, searching to express himself out of Doxa's impositions.

KEY WORDS: Roland Barthes, reader, text, author. 


\title{
EM TESE
}

Belo Horizonte, v. 9, p. I-28I, dez. 2005

\author{
REFERÊNCIAS BIBLIOGRÁFICAS
}

BAKHTINE, Mikhaïl. Esthétique et théorie du roman. Traduction de Daria 0livier. Paris: Gallimard, 1978. 492p.

BARTHES, Roland. Euvres complètes (1942-1965). Tome I. Paris: Seui1, 1993. 1611p.

BARTHES, Roland. Euvres complètes (1966-1973). Tome II. Paris: Seui1, 1994. 1757p.

BARTHES, Roland. Euvres complètes (1974-1980). Tome III. Paris: Seui1, 1995. 1371p.

BARTHES, Roland. Le Neutre, Cours au Collège de France (1977-1978). Paris: Seuil; IMEC, 2002. 272p.

BARTHES, Roland. O neutro: anotações de aulas e seminários ministrados no Collège de France, 1977-1978. Trad. Ivone Castilho Benedetti. São Paulo: Martins Fontes, 2003. Coleção Roland Barthes.

BLO0M, Harold. Gênio. Trad. José Roberto 0'Shea. Rio de Janeiro: Objetiva, 2003. 832p.

CARPENTIERS, Nicolas. La Lecture selon Barthes. Paris, Montréal: L'Harmattan, 1998. 192p.

COMMENT, Bernard. Roland Barthes, vers le neutre. Paris: Christian Bourgois, 2002. 336p.

DELEUZE, Gilles. Désir et plaisir. In: Magazine Littéraire. Paris, n. 325, oct. 1994. p. 57-65. (Dossier Michel Foucault).

ROUDINESCO, Elisabeth; PLON, Michel. Dicionário de Psicanâlise. Trad. Vera Ribeiro e Lucy Magalhães. Rio de Janeiro: Jorge Zahar, 1998. 874p. 